Check for updates

Cite this: RSC Adv., 2019, 9, 3816

\title{
A general route to modify diatomite with niobates for versatile applications of heavy metal removal $\uparrow$
}

Received 12th December 2018 Accepted 23rd January 2019

DOI: 10.1039/c8ra10186h

rsc.li/rsc-advances

\author{
Tianning Wang, Yunfei Yang, Jinshu Wang, (D) * Junshu Wu, (D) * Lingmin Sun, \\ Yucheng Du, Yongli Li and Hongyi Li (D)
}

A general solution-phase strategy is developed to synthesize nanostructure niobates such as $\mathrm{MnNb}_{2} \mathrm{O}_{6}$, $\mathrm{SnNb}_{2} \mathrm{O}_{6}$ and $\mathrm{ZnNb}_{2} \mathrm{O}_{6}$ on natural mineral diatomite for water environmental remediation. $\left(\mathrm{NH}_{4}\right)_{2} \mathrm{C}_{2} \mathrm{O}_{4}$ aqueous solution is the key to achieve a scalable and controllable synthesis of niobate/diatomite hybrid systems, which generates $\mathrm{NH}_{3} \cdot \mathrm{H}_{2} \mathrm{O}$ for surface etching activation of diatomite, and $\mathrm{H}_{2} \mathrm{C}_{2} \mathrm{O}_{4}$ for complexation dissolution of $\mathrm{Nb}_{2} \mathrm{O}_{5}$, enabling the heterogeneous crystallization process to proceed with controllable growth kinetics. First principle calculations indicate that both niobium atom and niobiumoxygen species have the lowest adsorption energy on $\mathrm{SiO}_{2}$ surface, and then induce the nucleating process of $\mathrm{Nb}-\mathrm{O}-\mathrm{Mn}$ (or $\mathrm{Zn}, \mathrm{Sn}$ ) networks. $\mathrm{Cr}(\mathrm{VI})$, Fe(III), and $\mathrm{Pb}(\mathrm{II})$ ions are taken as target pollutants to evaluate the water-cleaning ability of the niobate-modified diatomite. Possible mechanisms for the photoreduction of $\mathrm{Cr}(\mathrm{VI})$, physical adsorption of $\mathrm{Fe}(\mathrm{OH})_{3}$ colloids, and chemisorption of $\mathrm{Pb}(\Perp)$ ions are proposed on the basis of experimentally investigations. The possibility of combining the advantages of natural mineral diatomite and nanostructured niobates provides a highly robust and potential material system with versatile functionalities of heavy metal ion removal, demonstrating great promise for a wide range of water purification.

\section{Introduction}

Water contamination is one of the most urgent issues worldwide. Rapid industrialization and development, especially the excessive effluent of metal ions, exacerbates the problem of water pollution. Heavy metal ions like $\mathrm{Cr}(\mathrm{VI}), \mathrm{Fe}$ (III) and $\mathrm{Pb}$ (II) play vital roles in textile, paper, manufacturing and steel fabrication. ${ }^{1-3}$ Beyond their crucial functions in modern industry, these metal ions can be of great concern at elevated concentrations because of their toxicity as well as bioaccumulation tendencies. ${ }^{4}$ It is thus of great significance to design and synthesize effective and stable materials for removing these three metal ions by the preferred approaches from both scientific and practical perspectives. Natural minerals like zeolite, sepiolite, and attapulgite with high dispersity and more binding sites, are particularly suitable for use as both pristine adsorbents and carriers of active nanostructures. ${ }^{5-8}$ Diatomite is one of the most promising mineral materials for removing aqueous contaminants on account of its wide distribution, highly developed porosity, low cost and well adsorption performance. ${ }^{6}$ Derived from fossilized skeletons of diatoms, its main

The Key Lab of Advanced Functional Materials, Ministry of Education China, School of Materials Science and Engineering, Beijing University of Technology, Beijing 100022, China. E-mail: wangjsh@bjut.edu.cn; junshuwu@bjut.edu.cn; Fax: +86106739 1101; Tel: +861067391101

$\dagger$ Electronic supplementary information (ESI) available. See DOI: 10.1039/c8ra10186h component is amorphous silica along with small quantities of metallic oxides. ${ }^{9}$ Due to its great chemical and thermal stability, diatomite has emerged as an attractive support for stabilizing and dispersing nanomaterials (e.g. Fe/Ni metals, ${ }^{6} \mathrm{TiO}_{2}{ }^{7}$ graphdiyne, ${ }^{\mathbf{1 0}}$ etc.) to offer better removal efficiency and more active sites. It is also proved that these as-synthesized composited material systems show well synergistic effect in transferring contaminants to reactive sites and keeping them available for further interactions with metal ions, thus displaying superior water-cleaning activity, compared with separated nanostructures or diatomite. ${ }^{\mathbf{1 1}}$

Niobium ( $\mathrm{Nb}$ )-containing oxides have recently emerged as a family of promising functional alternative nanostructures for water treatment due to their interesting chemistry such as intrinsic high energy level of $\mathrm{Nb} 4 \mathrm{~d}$ orbital and distorted $\left[\mathrm{NbO}_{6}\right]$ octahedra. ${ }^{12,13}$ As a typical member of the niobium (Nb)containing oxides family, columbite-type structure possesses unique $\alpha-\mathrm{PbO}_{2}$-type structure with half occupied oxygen packing along $a$-axis in the octahedral. ${ }^{14}$ The stability of $\left[\mathrm{MO}_{6}\right]$ $(\mathrm{M}=\mathrm{Mn}, \mathrm{Zn})$ in lower oxidation states could generate amounts of oxygen vacancies. Therefore, the structure with abundant edge sites exhibits great water cleaning ability. ${ }^{12,15} \mathrm{SnNb}_{2} \mathrm{O}_{6}$ is another active niobate and has a typical froodite structure with two corner-sharing $\mathrm{NbO}_{6}$ octahedra and a distorted edgesharing $\mathrm{Sn}^{\mathrm{II}} \mathrm{O}_{8}$ square antiprism, owing to a stereo active lone electron pair of $\mathrm{Sn}(\mathrm{II})$. Hence, $\mathrm{SnNb}_{2} \mathrm{O}_{6}$ exhibits excellent photoactivity under visible light. ${ }^{16}$ Additionally, as a typical $2 \mathrm{D}$ 
layered material, $\mathrm{SnNb}_{2} \mathrm{O}_{6}$ can provide abundant interfacial contacts for heterogeneous adsorption. These two kinds of typical distorted structure (froodite-type and columbite-type) which possess abundant structural defects and active edge sites inspire us to investigate the elimination property for $\mathrm{Cr}(\mathrm{vI})$, $\mathrm{Fe}(\mathrm{III})$, and $\mathrm{Pb}$ (II) ions. Considering that the available niobate system still presents some drawbacks such as high synthesis cost and serious particle aggregation, it is alternative by immobilizing these niobate nanostructures on diatomite via solution-phase synthesis routes, which properly promotes affordable wastewater process development in practical applications.

Herein, we found that natural mineral diatomite was particularly suitable for loading nanostructures to building composited water-cleaning materials. We focus on synthetic tuning of niobate/diatomite hybrid systems using a general $\left(\mathrm{NH}_{4}\right)_{2} \mathrm{C}_{2} \mathrm{O}_{4}$-assisted solution-phase route. As an inorganic nonmetallic mineral, Earth-abundant diatomite meets the requirements of a scalable and cost-effective synthesis. More importantly, high-active niobate nanostructures can be crystallized on diatomite by facile tuning of metal salts or solvent (water or ethanol). The integration of active nanostructures with the natural mineral enhances the light-absorption and surface activity, thus accelerating the water purification processes. As a proof-of-concept applications taking advantage of the unique features of these hybrid materials, the as-obtained $\mathrm{MnNb}_{2} \mathrm{O}_{6}{ }^{-}$, $\mathrm{SnNb}_{2} \mathrm{O}_{6}-, \mathrm{ZnNb}_{2} \mathrm{O}_{6}$-diatomites were used in three typical processes for removing pollutants, i.e., photoreduction of $\mathrm{Cr}(\mathrm{vI})$ to $\mathrm{Cr}(\mathrm{III})$, the physical adsorption of $\mathrm{Fe}(\mathrm{OH})_{3}$ colloids to eliminate $\mathrm{Fe}(\mathrm{III})$, and direct chemisorption removal of $\mathrm{Pb}$ (II) ions, demonstrating their versatile water-cleaning functionalities. The synthesis protocol of integrating diatomite with controlled niobate nanostructures provides a highly robust and potential material system for environmental purification, demonstrating great promise for a wide range of heavy metal ion removal.

\section{Experimental}

\subsection{Materials}

The raw diatomite was obtained from Changbai Mountain, Jilin Province of China. Manganese(II) chloride $\left(\mathrm{MnCl}_{2} \cdot 4 \mathrm{H}_{2} \mathrm{O}\right)$, niobium oxide $\left(\mathrm{Nb}_{2} \mathrm{O}_{5}\right)$ and oxalic acid $\left(\mathrm{H}_{2} \mathrm{C}_{2} \mathrm{O}_{4} \cdot 2 \mathrm{H}_{2} \mathrm{O}\right)$ were purchased from Sinopharm Chemical Reagent Co., Ltd. Hydrofluoric acid $(\mathrm{HF})$, lead nitrate $\left(\mathrm{Pb}\left(\mathrm{NO}_{3}\right)_{2}\right)$, ferric trichloride hexahydrate $\left(\mathrm{FeCl}_{3} \cdot 6 \mathrm{H}_{2} \mathrm{O}\right)$ and aluminum nitrate nonahydrate $\left(\mathrm{Al}\left(\mathrm{NO}_{3}\right)_{3} \cdot 9 \mathrm{H}_{2} \mathrm{O}\right)$ were purchased from Tianjin Fuchen Chemical Reagent Factory. Tin(II) chloride $\left(\mathrm{SnCl}_{2} \cdot 2 \mathrm{H}_{2} \mathrm{O}\right)$, anhydrous ethanol $\left(\mathrm{C}_{2} \mathrm{H}_{5} \mathrm{OH}\right)$, Hydrofluoric acid $(\mathrm{HCl})$, sodium hydroxide $(\mathrm{NaOH})$, sodium nitrate $\left(\mathrm{NaNO}_{3}\right)$, sodium sulfate anhydrous $\left(\mathrm{Na}_{2} \mathrm{SO}_{4}\right)$ and sodium dihydrogen phosphate $\left(\mathrm{NaH}_{2} \mathrm{PO}_{4} \cdot 2 \mathrm{H}_{2} \mathrm{O}\right)$ were supplied by Beijing Chemical Reagent Research Company. Zinc nitrate hexahydrate $\left(\mathrm{Zn}\left(\mathrm{NO}_{3}\right)_{2} \cdot 6 \mathrm{H}_{2} \mathrm{O}\right)$ and ammonium oxalate $\left(\left(\mathrm{NH}_{4}\right)_{2} \mathrm{C}_{2} \mathrm{O}_{4}\right)$ were purchased from Xilong Chemical Co., Ltd. Cadmium nitrate tetrahydrate $\left(\mathrm{Cd}\left(\mathrm{NO}_{3}\right)_{2} \cdot 6 \mathrm{H}_{2} \mathrm{O}\right)$ was supported by Damao Chemical Reagent Factory. All chemicals used in this work were without further purification and the deionized water was used throughout this study.

\subsection{Preparation of samples}

Raw diatomite (RD) was prepared by a facile alkali treatment before subsequent synthesized procedure. Typically, $6.0 \mathrm{~g}$ RD was dispersed in $300 \mathrm{ml} 0.17 \mathrm{~mol} \mathrm{~L}^{-1} \mathrm{NaOH}$ solution at $90{ }^{\circ} \mathrm{C}$ and keep stirring for $2 \mathrm{~h}$. After separation from the dispersion, the $\mathrm{RD}$ was washed several times by water and anhydrous ethanol until $\mathrm{pH}$ value near neutral. After drying at $60^{\circ} \mathrm{C}$ for $6 \mathrm{~h}$, the alkali treated diatomite (ATD) was collected for subsequent procedure. In a typical procedure for $\mathrm{MnNb}_{2} \mathrm{O}_{6} / \mathrm{ATD}$ (MNOD) and $\mathrm{ZnNb}_{2} \mathrm{O}_{6} /$ ATD (ZNOD), amorphous $\mathrm{Nb}_{2} \mathrm{O}_{5} \cdot n \mathrm{H}_{2} \mathrm{O}$ was firstly prepared from $0.30 \mathrm{~g}$ commercial $\mathrm{Nb}_{2} \mathrm{O}_{5}$ powder (the synthesis process has been described in our previous work $\left.{ }^{\mathbf{1 7}}\right)$. Typically, $0.30 \mathrm{~g}$ commercial $\mathrm{Nb}_{2} \mathrm{O}_{5}$ was prepared in $3.0 \mathrm{ml} \mathrm{HF}(40 \%)$ and then loaded into a $20 \mathrm{ml}$ Telflon-lined stainless steel autoclave at $160{ }^{\circ} \mathrm{C}$ for $6 \mathrm{~h}$. After cooling down to room temperature, $10 \mathrm{ml}$ deionized water and $3.0 \mathrm{ml} \mathrm{NH} \mathrm{H}_{3} \cdot \mathrm{H}_{2} \mathrm{O}(25-28 \%)$ were dropped in this solution. After filtering and washing to neutral with water, the amorphous $\mathrm{Nb}_{2} \mathrm{O}_{5} \cdot n \mathrm{H}_{2} \mathrm{O}$ was dispersed in $10 \mathrm{ml}$ $\left(\mathrm{NH}_{4}\right)_{2} \mathrm{C}_{2} \mathrm{O}_{4}$ solution $\left(0.08 \mathrm{~mol} \mathrm{~L}^{-1}\right)$ at $80{ }^{\circ} \mathrm{C}$ under stirring for 3 min. $0.40 \mathrm{~g} \mathrm{MnCl}_{2} \cdot 4 \mathrm{H}_{2} \mathrm{O}$ (or $\mathrm{Zn}\left(\mathrm{NO}_{3}\right)_{2} \cdot 6 \mathrm{H}_{2} \mathrm{O}$ ) was slowly transferred into the above-mentioned solution. Keep stirring for $3 \mathrm{~min}$, then $0.20 \mathrm{~g}$ ATD was put into the homogeneous solution. The mixture was then stirred continuously for $5 \mathrm{~min}$ to immobilize the as-prepared colloids onto ATD. Afterwards, the final mixture was loaded into a $20 \mathrm{ml}$ Telflon-lined stainless steel autoclave and sealed by autoclave. The autoclave was heated at $180{ }^{\circ} \mathrm{C}$ for $24 \mathrm{~h}$ in an electric oven. After the autoclave was cooled down to room temperature, the final mixture was separated by filtration and rinsed with deionized water and anhydrous ethanol for three times, and dried at $60{ }^{\circ} \mathrm{C}$ for $6 \mathrm{~h}$. The synthesis procedure of $\mathrm{SnNb}_{2} \mathrm{O}_{6} / \mathrm{ATD}$ (SNOD) is almost the same as MNOD, except that $0.50 \mathrm{~g} \mathrm{SnCl} 2 \cdot 4 \mathrm{H}_{2} \mathrm{O}$ was dispersed in $10 \mathrm{ml}$ anhydrous ethanol in replace of $10.0 \mathrm{ml}$ deionized water.

\subsection{Characterization}

The crystallographic information and chemical composition of as-prepared niobate/diatomite samples were characterized by SHIMADZU XRD-7000 XRD diffractometer, equipped with $\mathrm{Cu}$ $\mathrm{K} \alpha$ radiation $(\lambda=0.154056 \mathrm{~nm})$ at a scanning speed of $4^{\circ} \mathrm{min}^{-1}$. A Hitachi S-4800N scanning electron microscopy (SEM) and JEM-2010 transmission electron microscopy (TEM) were applied to detect the structural and morphological information of samples. The optical properties were recorded on a UV-vis spectrophotometer (Shimadzu-3600 plus) in the wavelength range of $200-800 \mathrm{~nm}$ at room temperature. Fourier transform infrared spectroscopic (FT-IR) measurements were operated on a PerkinElmer spectrometer (spectrum 100) in the range of 400$4000 \mathrm{~cm}^{-1}$ at the resolution $4 \mathrm{~cm}^{-1}$. The samples were prepared by mixing $1 \mathrm{mg}$ of the as-prepared powder with $100 \mathrm{mg}$ of $\mathrm{KBr}$ and pressing the mixture into a thin film, and all samples were baseline corrected. Nitrogen adsorption/desorption tests were measured by a surface area and porosity analyzer (ASAP 2020 $(\mathrm{V} 4.00 \mathrm{H}))$ at $77 \mathrm{~K}$. And before the test, samples were degassed at $573 \mathrm{~K}$ for $3 \mathrm{~h}$. X-ray photoelectron spectroscopic (XPS) spectra of the samples were performed on ESCALAB 250Xi electron spectrometer with $\mathrm{Al} \mathrm{K} \alpha \mathrm{X}$-ray source. The $\mathrm{Fe}(\mathrm{III})$ and $\mathrm{Pb}$ (II) 
concentrations were determined by inductively coupled plasma atomic emission spectroscopic (ICP-AES, IRIS Intrepid ER/S). Zeta potentials measured at various $\mathrm{pH}$ values were tested by zeta potential analyzer (Malvern Nano-2S90).

\section{$2.4 \mathrm{Cr}(\mathrm{VI}), \mathrm{Fe}(\mathrm{III})$, and $\mathrm{Pb}$ (II) ion elimination tests}

The photocatalytic activities of niobate/diatomite were evaluated by using photoreduction removal of $\mathrm{Cr}(\mathrm{vI})$ under light irradiation. Briefly, $20 \mathrm{mg}$ niobate/diatomite powder was dispersed in 60-120 mg $\mathrm{L}^{-1} \mathrm{Cr}_{2} \mathrm{O}_{7}{ }^{2-}$ aqueous solution in a $100 \mathrm{ml}$ beaker, then the suspension was sonicated for $15 \mathrm{~s}$ and kept in dark for $1 \mathrm{~h}$ to establish an adsorption/desorption equilibrium between photocatalyst and $\mathrm{Cr}(\mathrm{vI})$ ions. Afterwards, $20 \mathrm{mg}$ oxalic acid was added into the solution as hole scavenger. ${ }^{12}$ Then the mixed solution was stirred under visible light irradiation (MNOD and SNOD, $300 \mathrm{~W}$ xenon lamp with an ultraviolet cutoff filter, $\lambda>420 \mathrm{~nm}$ ) or ultraviolet light irradiation $\left(\mathrm{ZnNb}_{2} \mathrm{O}_{6}, 300 \mathrm{~W}\right.$ xenon lamp with a visible-light cutoff filter, $\lambda<400 \mathrm{~nm}$ ). At a given reaction time, $3.0 \mathrm{ml}$ aliquot dispersions were taken for analysis, followed by filtration to remove precipitates. The obtained supernatant was detected by UV-vis spectrophotometer to determined $\mathrm{Cr}(\mathrm{vI})$ reduction at the absorbance peak of $350 \mathrm{~nm}$. The photocatalytic efficiency is describe by $\left[\eta=C / C_{\mathrm{o}} \times 100 \%=A / A_{\mathrm{o}} \times 100 \%\right]$, where $C_{0}$ and $C$ represents initial and current concentration of $\mathrm{Cr}_{2} \mathrm{O}_{7}{ }^{2-}$ solution, $A_{0}$ and $A$ corresponds to initial and current adsorption intensity.

The $\mathrm{Fe}(\mathrm{OH})_{3}$ colloids were prepared by the hydrolysis of $\mathrm{FeCl}_{3} \cdot 6 \mathrm{H}_{2} \mathrm{O}$ in boiling water. And the synthesis details of $\mathrm{Fe}(\mathrm{OH})_{3}$ colloids is exactly the same as the previously reported method. ${ }^{18}$ Specially, a certain amount of $\mathrm{FeCl}_{3} \cdot 6 \mathrm{H}_{2} \mathrm{O}$ was resolved in $5.0 \mathrm{~mL}$ deionized water. Then the as-prepared solution was transferred in $300 \mathrm{ml}$ boiling water and continued heating for $10 \mathrm{~min}$. After cooling down to room temperature, the $\mathrm{Fe}(\mathrm{OH})_{3}$ colloids was obtained. $50 \mathrm{ml}$ of $\mathrm{Fe}(\mathrm{OH})_{3}$ colloids or $\mathrm{Pb}\left(\mathrm{NO}_{3}\right)_{2}$ aqueous solution with a certain concentration was added into a $100 \mathrm{ml}$ beaker. $20 \mathrm{mg}$ of the asprepared sample was added into the above colloids or aqueous solution, and then the beaker was sonicated for $15 \mathrm{~s}$ to make a better dispersion. At a certain interval, $3 \mathrm{ml}$ aliquot dispersions were filtered by a filter to obtain the filtrate for further analysis. To prevent the hydrolysis of $\mathrm{Fe}(\mathrm{III})$, all the $\mathrm{Fe}(\mathrm{OH})_{3}$ colloid after adsorption were added $0.1 \mathrm{ml} \mathrm{HCl} \mathrm{(38} \mathrm{wt \% ).} \mathrm{The}$ $\mathrm{Fe}(\mathrm{III})$ and $\mathrm{Pb}$ (II) concentrations in the filtrates were analyzed by the ICP-AES technique. The adsorption capacity of $\mathrm{Fe}(\mathrm{OH})_{3}$ colloid was determined by the unit change between $\mathrm{Fe}(\mathrm{OH})_{3}$ and $\mathrm{Fe}(\mathrm{III})$. The $\mathrm{pH}$ value was adjusted by $1 \mathrm{~mol} \mathrm{~L}^{-1} \mathrm{HCl}$ or $1 \mathrm{~mol} \mathrm{~L}^{-1} \mathrm{NaOH}$ aqueous solution in this work.

\subsection{First principle calculation of $\mathrm{Mn}, \mathrm{Sn}, \mathrm{Zn}, \mathrm{Nb}$ atoms adsorption on silica}

The adsorption energy of $\mathrm{Mn}, \mathrm{Sn}, \mathrm{Zn}, \mathrm{Nb}$ on silica was calculated with the projected augmented wave (PAW) formalism of DFT, as implemented in the Vienna $\mathrm{Ab}$ initio simulation package (VASP). ${ }^{19}$ (101) face of $\mathrm{SiO}_{2}$ is selected for the calculation considering that it is the observed strongest peak in the
XRD pattern of RD. Perdew-Burke-Ernzerhof of (PBE) exchange-correlation (XC) function of the generalized gradient approximation (GGA) was employed for all our calculations, ${ }^{19}$ which are shown to be very effective for cluster ${ }^{20}$ and surface calculations. ${ }^{21}$ The cut-off energy of $600 \mathrm{eV}$ for plane wave basis expansion was used. The model system used in this work consists of $4 \times 4$ super cell with a vacuum layer of $15 \AA$ in the $Z$ direction to exterminate the interaction between adjacent layers. The Brillouin zone was sampled using $\Gamma$-centered $7 \times 7$ $\times 1 k$-point grid and the atomic relaxations were continued until the Hellmann-Feynman forces acting on the atoms were less than $0.01 \mathrm{eV}^{-1}$ and the total energy changes were less than $10^{-6} \mathrm{eV}^{22}$

\section{Results and discussion}

XRD analysis of the as-prepared MNOD, SNOD and ZNOD samples are shown in Fig. 1 and $\mathrm{S} 1 . \dagger$ The main diffraction peaks of MNOD at $24.1^{\circ}, 29.8^{\circ}, 51.1^{\circ}$, and $52.7^{\circ}$ correspond to (130), (131), (330), and (261) planes of manganocolumbite $\mathrm{MnNb}_{2} \mathrm{O}_{6}$ (JCPDS\# 33-0899) (Fig. 1(a) and S1(a)†), respectively. No impurity peaks of manganese oxide or $\mathrm{Nb}_{2} \mathrm{O}_{5}$ are detected, indicating that pure $\mathrm{MnNb}_{2} \mathrm{O}_{6}$ can be successfully crystallized on ATD. The XRD patterns also demonstrate that other niobates, $\mathrm{ZnNb}_{2} \mathrm{O}_{6}$ (JCPDS\# 76-1827) (Fig. 1 and $\mathrm{S} 1(\mathrm{~b}) \dagger$ ) and $\mathrm{SnNb}_{2} \mathrm{O}_{6}$ (JCPDS\# 841810) (Fig. 1 and $\mathrm{S} 1(\mathrm{c}) \dagger$ ), are grown on ATD, indicating the generalization of our designed reaction system for niobate/ diatomite composites. The light absorption properties of niobate/diatomite are shown in Fig. 1(b). The photoresponse area of MNOD and SNOD locates in the visible region with the absorption edges of $630 \mathrm{~nm}$ and $540 \mathrm{~nm}$, respectively, while ZNOD shows an ultraviolet absorption below $370 \mathrm{~nm}$. Compared with ATD sample with poor light-harvesting ability, the loading of niobates enhances the absorption intensity and extends photoresponse range. The inset of Fig. 1(b) displays band gaps of MNOD, SNOD and ZNOD. According to Tauc plot of $(\alpha h v)^{2}$ versus energy $(h v)$, the band gap energy of MNOD, SNOD and ZNOD is estimated about $2.41 \mathrm{eV}, 2.89 \mathrm{eV}$ and $3.80 \mathrm{eV}$, respectively. The nitrogen adsorption-desorption isotherms of MNOD, SNOD and ZNOD are displayed in Fig. 1(c), which are assigned as type III, mainly due to mesoporous structure and an aggregate character of sheet-like particles. ${ }^{23}$ The adsorption capacity of niobate/diatomite exhibits a moderate growth at low relative pressure, and then a steady increase is observed in high relative pressure range of 0.6-1.0, which is attributed to smaller crystallite and much rough surface in comparison to that of ATD. The BET surface area increases from 12.7 (ATD) to $49.9 \mathrm{~m}^{2} \mathrm{~g}^{-1}$ for MNOD, $52.9 \mathrm{~m}^{2} \mathrm{~g}^{-1}$ for ZNOD, and $64.0 \mathrm{~m}^{2} \mathrm{~g}^{-1}$ for SNOD. FT-IR spectra show the details of the synthesized niobate/diatomite samples at 400$1800 \mathrm{~cm}^{-1}$ (Fig. 1(d) and S2 $\dagger$ ). Three strong peaks of MNOD, ZNOD and SNOD are reflected in the absorption spectra, with wave number of $447 \mathrm{~cm}^{-1}$ assigned to the $\mathrm{Si}-\mathrm{O}-\mathrm{Si}$ function group. The peaks located at $792 \mathrm{~cm}^{-1}$ and $1070 \mathrm{~cm}^{-1}$ belong to the bending vibration and symmetrical stretching vibration of $\mathrm{Si}-\mathrm{O}$ functional group. ${ }^{24}$ For MNOD, the peak at $527 \mathrm{~cm}^{-1}$ is caused by the vibration between $\mathrm{Mn}$ and $\mathrm{O}^{25}$ The two 
absorption peaks appeared at $570 \mathrm{~cm}^{-1}$ and $646 \mathrm{~cm}^{-1}$ are attributed to the vibration of $\mathrm{Sn}-\mathrm{O}$ bonds of SNOD. ${ }^{26,27}$ The absorption observed at $566 \mathrm{~cm}^{-1}$ in ZNOD is corresponded to the stretching of $\mathrm{Zn}-\mathrm{O}$ bonds. ${ }^{28}$ These FT-IR spectra further confirm the generation of $\mathrm{MnNb}_{2} \mathrm{O}_{6}, \mathrm{SnNb}_{2} \mathrm{O}_{6}$, and $\mathrm{ZnNb}_{2} \mathrm{O}_{6}$ on diatomite surface.

The detail of morphology exhibits uniform flower-like $\mathrm{MnNb}_{2} \mathrm{O}_{6}$ particles on diatomite surface (Fig. 2( $\left.\mathrm{a}_{1}, \mathrm{a}_{2}\right)$ and $\mathrm{S} 3\left(\mathrm{a}_{1}, \mathrm{a}_{2}\right), \uparrow$ suggesting that the heterogeneous nucleation and crystallization processes of $\mathrm{MnNb}_{2} \mathrm{O}_{6}$. The high magnification image reveals that $\mathrm{MnNb}_{2} \mathrm{O}_{6}$ particle consists of nanosheets with the intrinsic six fold symmetry of columbite structure. The sheet-shaped structure is well crystallized with resolved lattice fringes having interplaner spacing of $0.306 \mathrm{~nm}$ and $0.368 \mathrm{~nm}$ (Fig. 2(a $\left.\mathrm{a}_{3}\right)$, which well match (311) and (310) planes of $\mathrm{MnNb}_{2} \mathrm{O}_{6}$ (JCPDS\# 33-0899), respectively. As shown in Fig. 2(b $\left.b_{1}, b_{2}\right)$ and $\mathrm{S} 3\left(\mathrm{~b}_{1}, \mathrm{~b}_{2}\right), \uparrow$ the $\mathrm{ZnNb}_{2} \mathrm{O}_{6}$ sample has a similar morphology feature with hexagon-like aggregated nanoparticles. Fringes of $d=0.298 \mathrm{~nm}$ and $d=0.374 \mathrm{~nm}$ (Fig. $\left.2\left(\mathrm{~b}_{3}\right)\right)$ are well indexed to the (311) and (111) planes of $\mathrm{ZnNb}_{2} \mathrm{O}_{6}$, respectively. Those $\mathrm{SnNb}_{2} \mathrm{O}_{6}$ particles grown on diatomite exhibit wrinkled lamellar morphology with smooth surface and well-defined edge (Fig. 2( $\left.c_{1}, c_{2}\right)$ and $\mathrm{S} 3\left(\mathrm{c}_{1}, \mathrm{c}_{2}\right) \dagger$ ). The lattice spacing of $\mathrm{SnNb}_{2} \mathrm{O}_{6}$ sheet is $0.305 \mathrm{~nm}$ (Fig. $3\left(\mathrm{c}_{3}\right)$, corresponding to the lattice spacing of (311) plane. Notably, few irregular aggregates can be found in these niobate modified ATD samples, suggesting alkali $(\mathrm{NaOH})$ treatment of diatomite has a great impact on the crystallization of the well-defined niobates, which generates abundant nucleation sites in the liquid-phase synthesis procedure compared with the samples prepared by $\mathrm{RD}$ (Fig. S4†). As a strong alkaline, $\mathrm{NaOH}$ etches diatomite surface by breaking $\mathrm{Si}-\mathrm{O}-\mathrm{Si}$ bonds to generating highly active surface that enables the heterogeneous crystallization process of niobate nanostructures.

Further insights into the structure of the niobate/diatomite system are obtained from their XPS analysis. Fig. 3(a) displays the full survey scan of MNOD, ZNOD and SNOD. The signals of $\mathrm{Nb}, \mathrm{O}, \mathrm{Si}, \mathrm{Mn}, \mathrm{Zn}$ and $\mathrm{Sn}$ can be clearly detected in these asprepared samples. The $\mathrm{Nb} 3 \mathrm{~d}$ high resolution scan of niobate/ diatomite (Fig. 3(b)) shows two typical $\mathrm{Nb} 3 \mathrm{~d}_{5 / 2}$ and $\mathrm{Nb} 3 \mathrm{~d}_{3 / 2}$ peaks located at $206.7 \mathrm{eV}$ and $209.5 \mathrm{eV}$, demonstrating that the oxidation state of $\mathrm{Nb}$ element is $\mathrm{Nb}(\mathrm{v}) \cdot{ }^{13}$ In the high-resolution spectra of Mn 2p (Fig. 3( $\left.c_{1}\right)$ ), four subpeaks can be observed after fitting: two peaks centered at $639.5 \mathrm{eV}$ and $651.7 \mathrm{eV}$ are assigned to the binding energy of $\mathrm{Mn}(\mathrm{II})$, while the other two peaks at $640.8 \mathrm{eV}$ and $653.1 \mathrm{eV}$ correspond to the signal of $\mathrm{Mn}$ (III). It means that there is oxygen deficiencies existed in the MNOD. ${ }^{12}$ The $\mathrm{O} 1 \mathrm{~s}$ high-resolution spectra can be deconvoluted
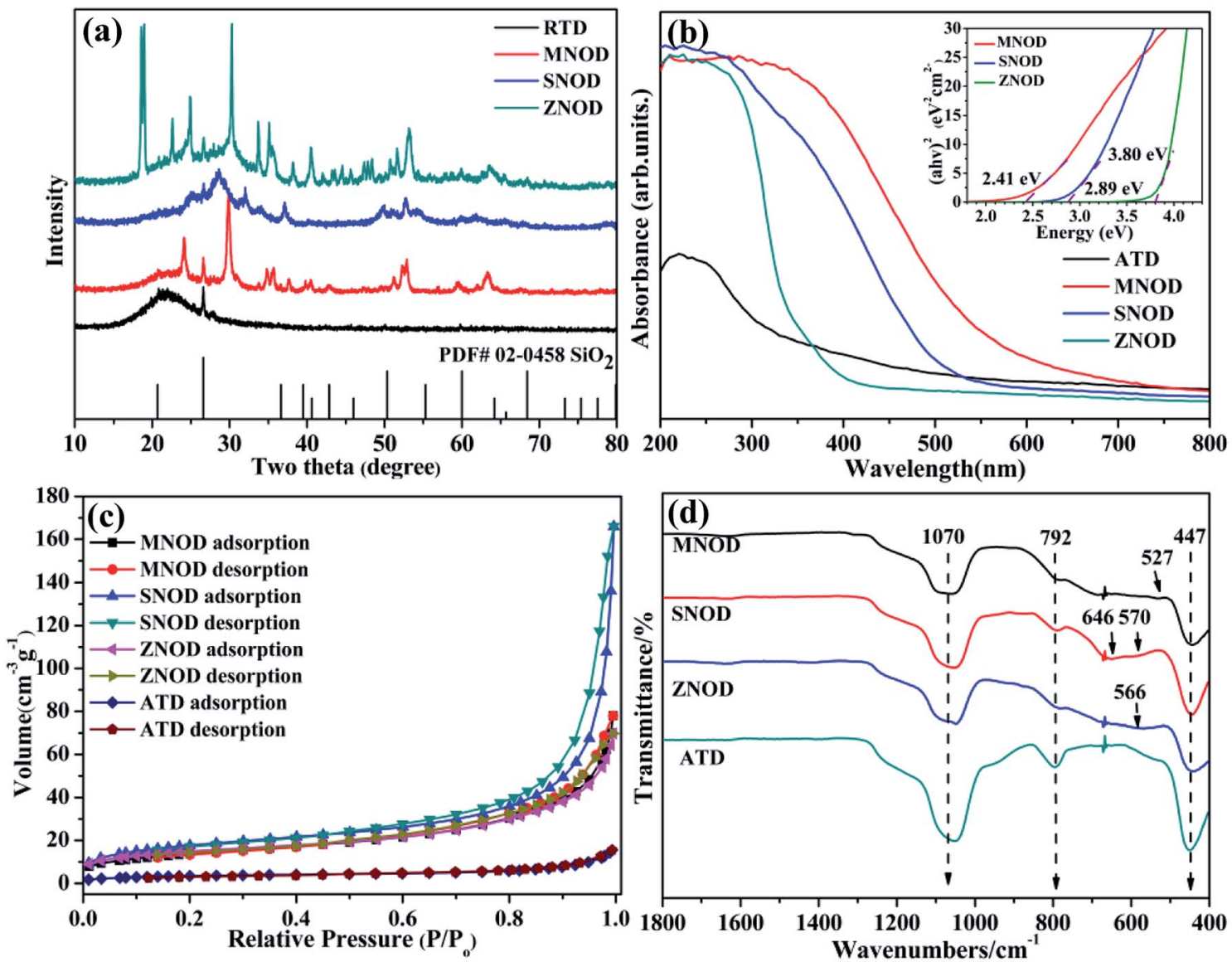

Fig. 1 (a) XRD patterns, (b) UV-vis absorption spectra, (c) nitrogen sorption isotherms, and (d) FT-IR spectra of the as-prepared MNOD, SNOD and ZNOD. 

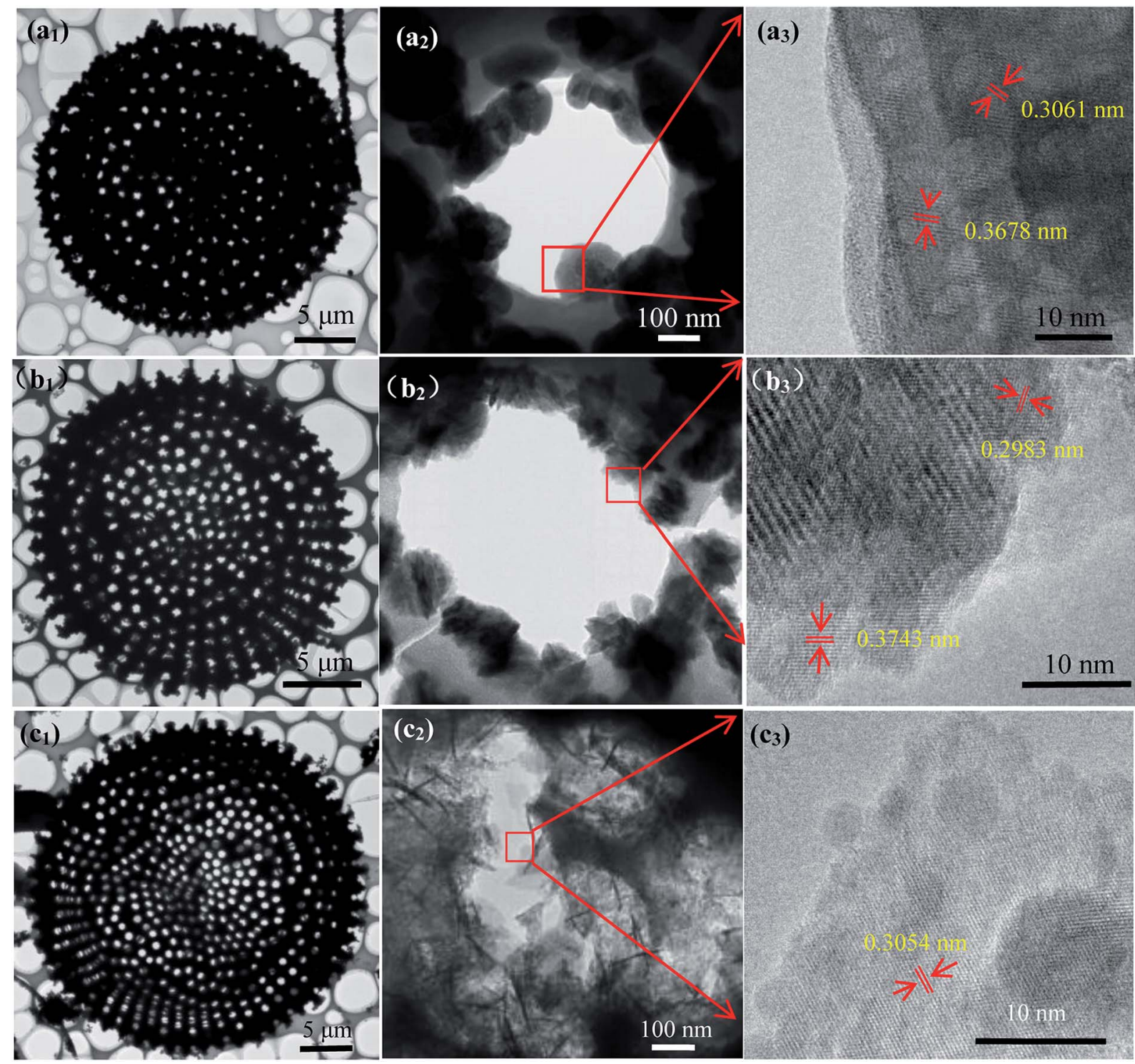

$\left(c_{3}\right)$

Fig. 2 TEM and HRTEM images of $\left(a_{1}-a_{3}\right)$ MNOD, $\left(b_{1}-b_{3}\right)$ ZNOD and $\left(c_{1}-c_{3}\right)$ SNOD.

into three peaks located at $530.3 \mathrm{eV}, 531.8 \mathrm{eV}$ and $532.9 \mathrm{eV}$ (Fig. $3\left(c_{2}\right)$ ), assigned to the lattice oxygen, surface hydroxyl oxygen and $\mathrm{Si}-\mathrm{O}-\mathrm{Si}$ binding, respectively. ${ }^{29}$ The main peaks of $\mathrm{Si}$ $2 \mathrm{p}$ in MNOD attribute to silicious species of $\mathrm{Si}-\mathrm{O}-\mathrm{Si}(102.1 \mathrm{eV})$, $\mathrm{Si}-\mathrm{OH}(103 \mathrm{eV}), \mathrm{Si}-\mathrm{O}-\mathrm{C}(103.4 \mathrm{eV})$, and $\mathrm{SiO}_{4}(104 \mathrm{eV})$ (Fig. 3( $\left.\left.\mathrm{c}_{3}\right)\right)^{30,31}$ Similar analyses were performed on the ZNOD and SNOD samples. As depicted in Fig. S5 $\left(\mathrm{a}_{1}\right), \dagger$ the peak located at $1021.8 \mathrm{eV}$ is characteristic of $\mathrm{Zn} 2 \mathrm{p}_{3 / 2}$ in $\mathrm{ZNOD},{ }^{32}$ and the high resolution scan shows two typical binding energies $(486.3 \mathrm{eV}$ and $494.7 \mathrm{eV}$ ) of Sn 3d in SNOD (Fig. S5(b $\left.\mathrm{b}_{1}\right) \dagger$ ). ${ }^{33}$

Diatomite has a similar nature to amorphous silica with acid sites and various hydroxyl species on its surface, including isolated hydroxyl groups and H-bonded hydroxyl groups, which can be ascribed to the coordination to the silicon atom in its structure. In aqueous solution, the surface $\mathrm{Si}-\mathrm{OH}$ groups are easily hydrolyzed into $\mathrm{Si}-\mathrm{O}-$, resulting in electronegative surface which is beneficial for the adsorption of metal-ion-concluding species for nucleation. Generally, the impurity in the natural diatomite is considered as the interference on the uptake of metal ions. In view of optimization for the adsorption process, alkali treatment for impurity becomes a necessity. Although the surface area of diatomite is slightly changed (RD: $10.2 \mathrm{~m}^{2} \mathrm{~g}^{-1}$, ATD: $12.9 \mathrm{~m}^{2} \mathrm{~g}^{-1}$ ), the surface impurity in RD is removed and soluble $\mathrm{SiO}_{4}{ }^{2-}$ species are generated after $\mathrm{NaOH}$ washing. ${ }^{34}$ More importantly, the number of surface functional groups including $\mathrm{Si}-\mathrm{O}-$ and surface $\mathrm{OH}^{-}$is increased. The detailed FTIR spectrum in Fig. 4(a) demonstrates that the vibration peaks located in $792 \mathrm{~cm}^{-1}$ (Si-O- bending vibration) and $1070 \mathrm{~cm}^{-1}$ (Si-O symmetrical stretching vibration) show remarkable enhancement, and the $\mathrm{O}$ 1s of high resolution XPS scan (Fig. 4(b) and S6†) also reveals noticeable intensity improvement of surface hydroxyl. The surface activation accelerates the heterogeneous nucleation and crystallization of niobates, which is a more energetically favored process than the generation of 

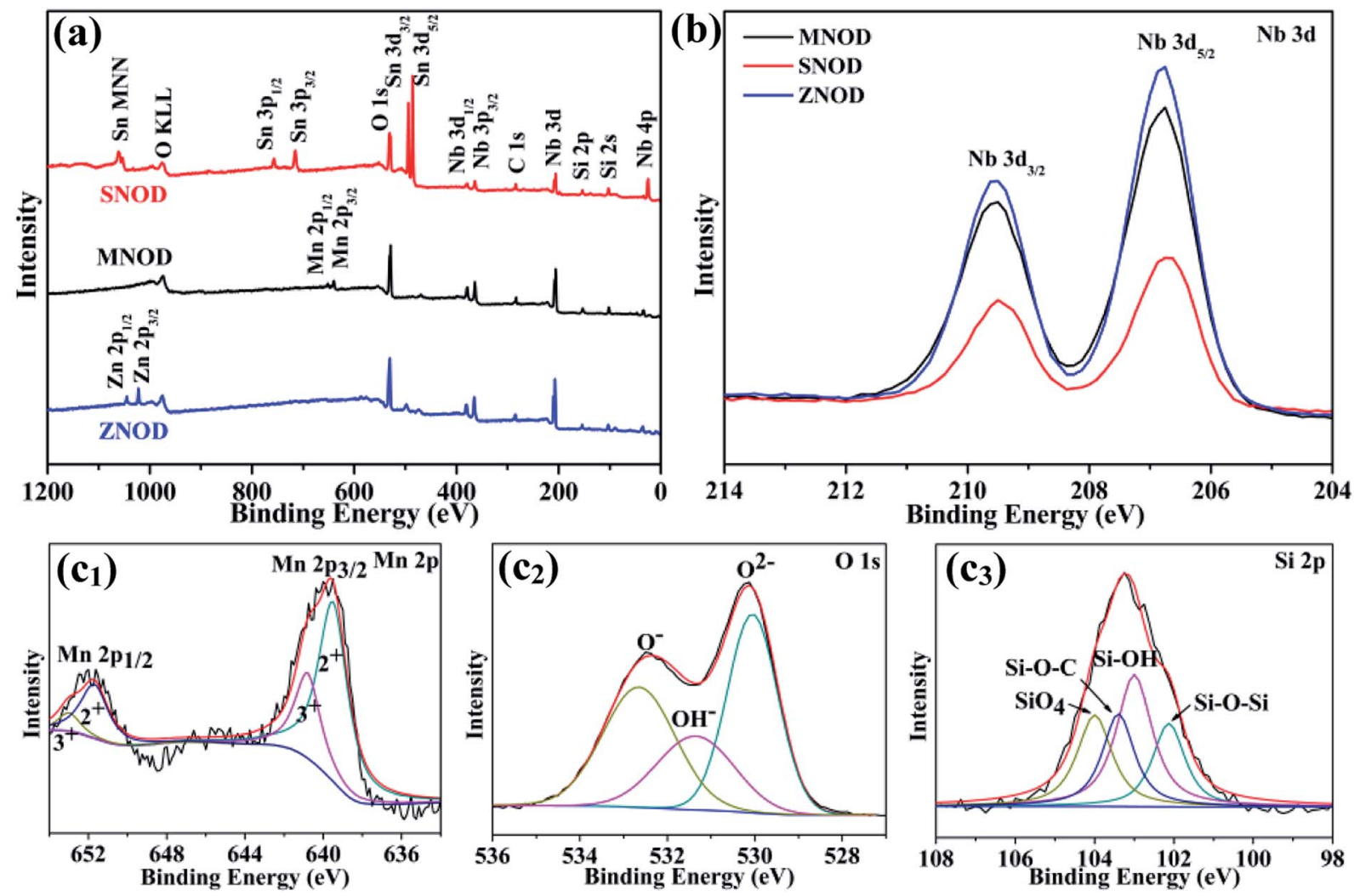

Fig. 3 (a) XPS survey scan and (b) high resolution XPS scan of Nb $3 d$ in MNOD, SNOD and ZNOD. $\left(c_{1}-c_{3}\right)$ Mn $2 p\left(c_{1}\right), O 1 s\left(c_{2}\right)$, and $S i 2 p\left(c_{3}\right)$ in MNOD.

new solid particles via the heterogeneous growth. Without surface activation of $\mathrm{RD}$, homogeneous precipitates and particle aggregation of niobate are frequently observed (Fig. S4†), indicating low efficiency for heterogeneous crystallization of niobates on RD. Moreover, both FT-IR (Fig. 4(c)) and XPS (Fig. 4(d)) results exhibit that the peak intensity of Si-O- functional groups and surface hydroxyls weakens with the reaction time, indicating their key roles for the induced crystallization of niobate guests..$^{35}$ More specifically, the bonding energy of lattice oxygen has slight increase owing to newly formed chemical bonds in ATD-niobate hybrid systems. Knowledge on the activation can potentially lead to control over early crystallization of the resulting niobate nanostructures. Concisely, the main questions are the following: (1) owing to structural and composition complexity of ternary oxides, which metal ions is preferentially adsorbed and bonded on ATD for the heterogeneous nucleation? (2) What is the growth mechanism, especially the role of $\left(\mathrm{NH}_{4}\right)_{2} \mathrm{C}_{2} \mathrm{O}_{4}$ in the general solution-phase synthesis?

The adsorption energy $\left(E_{\mathrm{ad}}\right)$ of $\mathrm{Nb}$ atoms on $\mathrm{SiO}_{2}(101)$ face were calculated with PBE exchange-correlation (XC) function of GGA, and Mn, Zn, Sn atoms were took as the comparison. Specially, the different atoms were placed on the same parallel surface according to calculations (Fig. 5(a)). The calculation results (Table 1) indicate that the adsorption of $\mathrm{Nb}$ atom $(-6.82$ eV) owns a lowest $E_{\text {ad }}$ compared with other three atoms, meaning that on the $\mathrm{SiO}_{2}$ surface $\mathrm{Nb}$ atoms would band together with $\mathrm{O}$ atoms more preferentially than the other three atoms. In the case of niobate, niobium is not in monatomic form but is bonded to oxygen. Therefore, the $E_{\text {ad }}$ would be influenced by the boned oxygen atoms. So the influence on $\mathrm{Nb}$ adsorption of bonded oxygen atoms was also taken into consideration (Fig. 5(b) and Table 1). It is deduced that the addition of oxygen atoms could promote the adsorption of four atoms in different extent, but does not reverse the order and adsorption preference. It follows that niobium can be adsorbed on the diatomite $\left(\mathrm{SiO}_{2}\right)$ surface much more easily and takes the lead in nucleating process, and then $\mathrm{Nb}-\mathrm{O}-\mathrm{Mn}$ (or $\mathrm{Zn}, \mathrm{Sn}$ ) network is generated in the separate heterogeneous crystallization process which is responsible to the built of niobate nanostructures on ATD. The dissolution of $\mathrm{Nb}_{2} \mathrm{O}_{5}$ is favorable for preparing niobates on ATD considering that the starting materials can be dissolved homogeneously and that the reagents have sufficient time to react with metal (Mn, Zn, Sn) salts. $\mathrm{Nb}_{2} \mathrm{O}_{5}$ is insoluble in pure water owing to its chemical inertness and high stability. $\mathrm{H}_{2} \mathrm{C}_{2} \mathrm{O}_{4}$ is produced in situ as a hydrolysis product by the introduction of $\left(\mathrm{NH}_{4}\right)_{2} \mathrm{C}_{2} \mathrm{O}_{4}$ (eqn (1)), and acts as a chemical etchant of $\mathrm{Nb}_{2} \mathrm{O}_{5}$ to form peroxocarboxylate-niobium complexes $\left(\left[\mathrm{NbO}\left(\mathrm{C}_{2} \mathrm{O}_{4}\right)_{x} \cdot y \mathrm{H}_{2} \mathrm{O}\right]^{(2 x-3)-}, x=\right.$ 2 or 3) with $\alpha$-hydroxyl organic acids as chelating agents. $\mathrm{Nb}-\mathrm{O}$ groups are generated in the complexation reactions (eqn (2)), ${ }^{36}$ resulting in high $\mathrm{Nb}-\mathrm{O}$ concentration regions around the ATD with abundant surface $\mathrm{Si}-\mathrm{OH}$ (or $\mathrm{Si}-\mathrm{O}-$ ) groups which serve as the active sites for the opening up of new nucleation and the 

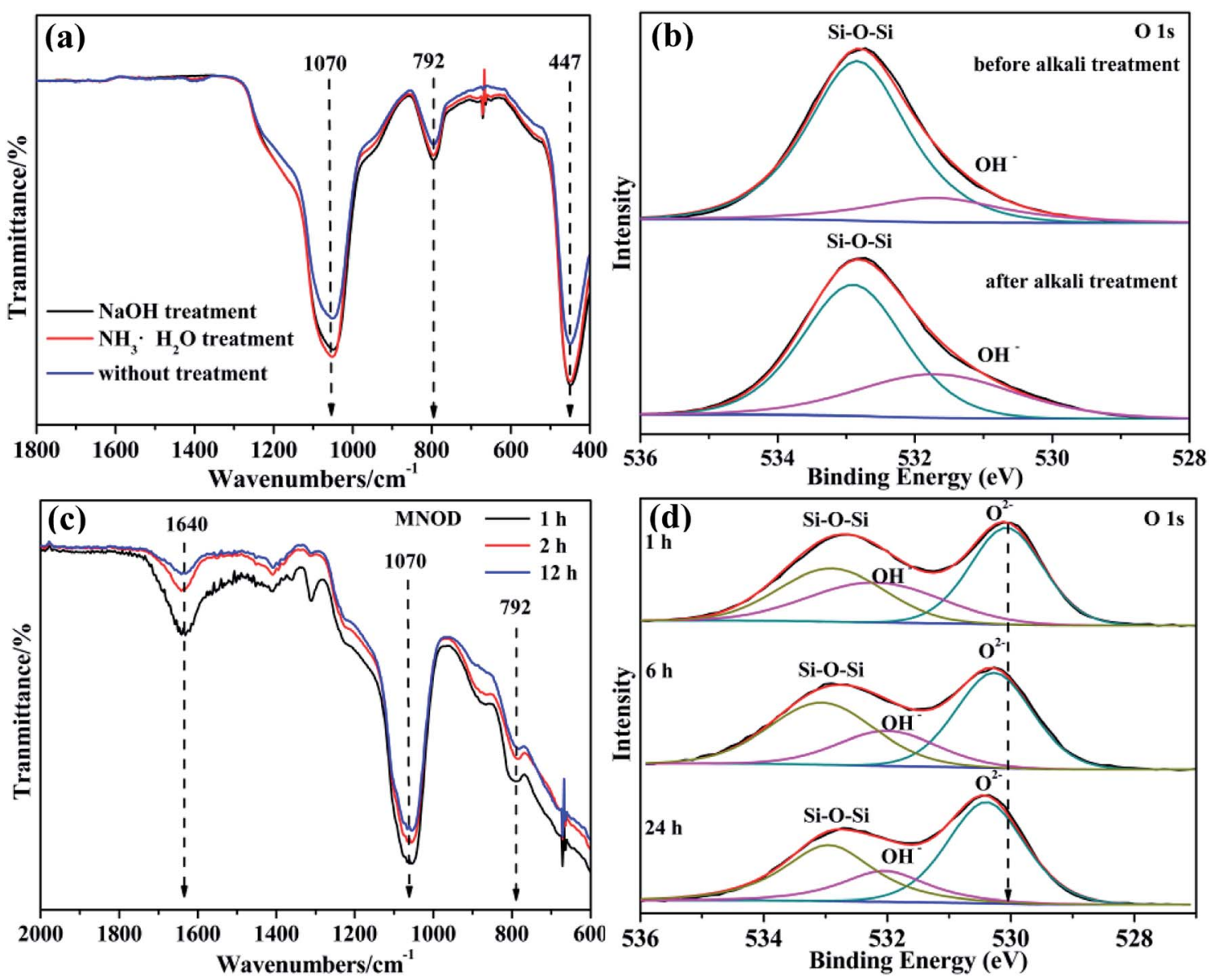

Fig. 4 (a) FT-IR spectra and (b) O 1s high resolution XPS scan of RD and ATD. (c) FT-IR spectra and (d) O 1s high resolution XPS scans of MNOD in different reaction time.

subsequent surface heterogeneous crystallization for MNOD, ZNOD and SNOD.

$$
\left(\mathrm{NH}_{4}\right)_{2} \mathrm{C}_{2} \mathrm{O}_{4}+2 \mathrm{H}_{2} \mathrm{O} \leftrightharpoons 2 \mathrm{NH}_{3} \cdot \mathrm{H}_{2} \mathrm{O}+\mathrm{H}_{2} \mathrm{C}_{2} \mathrm{O}_{4}
$$

$$
\left[\mathrm{NbO}\left(\mathrm{C}_{2} \mathrm{O}_{4}\right)_{x} \cdot y \mathrm{H}_{2} \mathrm{O}\right]^{(2 x-3)-} \leftrightharpoons \mathrm{NbO}^{3+}+x \mathrm{C}_{2} \mathrm{O}_{4}^{2-}+y \mathrm{H}_{2} \mathrm{O}
$$
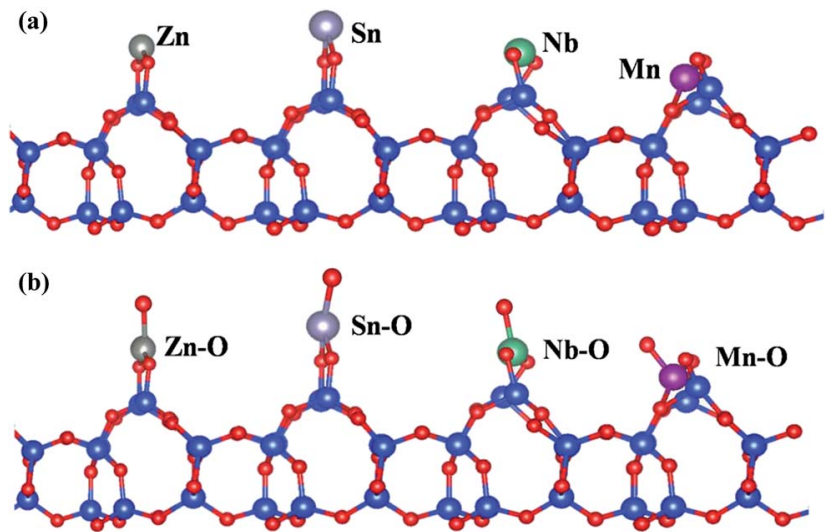

Fig. 5 The adsorption of (a) different atoms ( $\mathrm{Zn}, \mathrm{Sn}, \mathrm{Nb}, \mathrm{Mn}$ ) and (b) their groups including $\mathrm{O}$ atom on the diatomite (101) face. The blue, red, gray, purple, green and pink color represents the $\mathrm{Si}, \mathrm{O}, \mathrm{Zn}, \mathrm{Sn}, \mathrm{Nb}$ and $\mathrm{Mn}$ atom.
Furthermore, $\left(\mathrm{NH}_{4}\right)_{2} \mathrm{C}_{2} \mathrm{O}_{4}$ also play a dominant role in continuously providing surface hydroxyl for $\mathrm{Nb}-\mathrm{O}$ adsorption and subsequent niobate nucleation. $\mathrm{NH}_{3} \cdot \mathrm{H}_{2} \mathrm{O}$ is consumed from the very beginning of the chemical reactions due to surface dissolution of ATD to form active micro-sized zones, and there should be a dynamic equilibrium between the etching consumption of $\mathrm{NH}_{3} \cdot \mathrm{H}_{2} \mathrm{O}$ by ATD and complexation of $\mathrm{C}_{2} \mathrm{O}_{4}{ }^{2-}$ with $\mathrm{Nb}-\mathrm{O}$ groups, where ATD stays in the form of high-energy surface owing to surface etching reaction of $\mathrm{NH}_{3} \cdot \mathrm{H}_{2} \mathrm{O}$, allowing that the dissolution of $\mathrm{Nb}_{2} \mathrm{O}_{5}$ and $\mathrm{H}_{2} \mathrm{C}_{2} \mathrm{O}_{4}$ complexation proceed to activate the supply of $\mathrm{Nb}-\mathrm{O}$ units of niobate growth. Tuning the synergistic effects of these two concurrent but separate processes changes the etching rate of ATD and the growth kinetics of niobate, and thus enables the heterogeneous crystallization process to proceed at an appreciable rate to form various nanostructures. Experimentally, at a fixed concentration

Table 1 The $E_{\mathrm{ad}}$ of different atoms $(\mathrm{A}=\mathrm{Nb}, \mathrm{Mn}, \mathrm{Sn}, \mathrm{Zn})$ and their oxygen atom bonded species on the diatomite (101) face

\begin{tabular}{lrrrr}
\hline & $\mathrm{Nb}$ & $\mathrm{Mn}$ & $\mathrm{Sn}$ & \multicolumn{1}{c}{$\mathrm{Zn}$} \\
\hline$E_{\text {ad }}(\mathrm{A}) / \mathrm{eV}$ & -6.82 & -5.18 & -2.96 & -0.27 \\
$E_{\text {ad }}(\mathrm{A}-\mathrm{O}) / \mathrm{eV}$ & -20.53 & -18.57 & -14.99 & -11.60
\end{tabular}



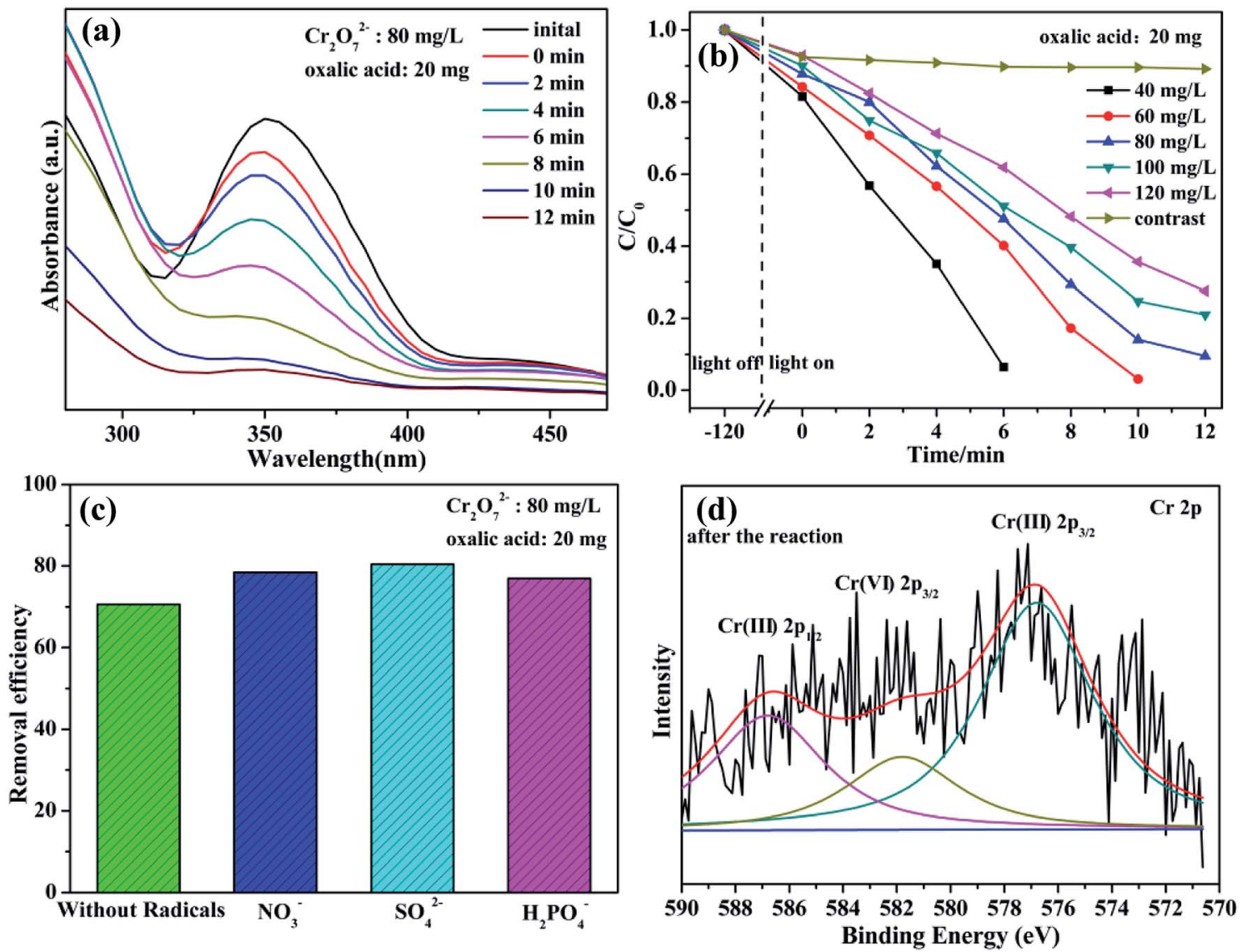

Fig. 6 (a) UV-vis spectra of $\mathrm{Cr}_{2} \mathrm{O}_{7}{ }^{2-}$ solution $\left(80 \mathrm{mg} \mathrm{L}^{-1}\right.$ ) as a function of visible-light irradiation time (MNOD: $20 \mathrm{mg}$ ). (b) Influence of $\mathrm{Cr}_{2} \mathrm{O}_{7}{ }^{2-}$ concentration and $(c)$ inorganic anions ( $t=10 \mathrm{~min}$ ) using MNOD (20 mg). (d) High resolution XPS scan of Cr $2 p$ in MNOD after photoreduction.

of $\left(\mathrm{NH}_{4}\right)_{2} \mathrm{C}_{2} \mathrm{O}_{4}\left(0.08 \mathrm{~mol} \mathrm{~L}^{-1}\right)$ while replacing $\mathrm{MnCl}_{2}$ by $\mathrm{MgCl}_{2}$, $\mathrm{MgNb}_{2} \mathrm{O}_{6}$ nanosheets were also grown on ATD although concomitant $\mathrm{MgC}_{2} \mathrm{O}_{4}$ impurity was found (Fig. S7†), further confirming that the developed approach is remarkably simple yet versatile for effectively generating niobate coatings crystallized on ATD with a high level of control and flexibility.

$\mathrm{Cr}(\mathrm{vI})$ is a typical kind of high soluble heavy metal contaminant in industry effluents. Photocatalytic reduction of $\mathrm{Cr}(\mathrm{vI})$ into $\mathrm{Cr}(\mathrm{III})$ is one of effective approaches frequently chosen for $\mathrm{Cr}(\mathrm{vI})$ pollution deep elimination owing to nontoxicity, less sludge as well as environmental friendliness. ${ }^{37}$ These as-synthesized niobate/diatomite materials are used for photocatalytic conversion of $\mathrm{Cr}(\mathrm{VI})$ into $\mathrm{Cr}(\mathrm{III})$ with the assistance of oxalic acid under light illumination. High photocatalytic performance is first confirmed by visual observation of peak intensity weakening within the reaction of 12 min (Fig. 6(a)). Notably, $80 \mathrm{mg} \mathrm{L}^{-1} \mathrm{Cr}_{2} \mathrm{O}_{7}{ }^{2-}$ solution is dramatically reduced to $\mathrm{Cr}(\mathrm{III})$ via MNOD sample $(20 \mathrm{mg})$ under visible light $\left(25^{\circ} \mathrm{C}\right)$. Additionally, under the conditions of weak natural sun light irradiation $(35$ $\left.{ }^{\circ} \mathrm{C}\right), 80 \mathrm{mg} \mathrm{L}{ }^{-1} \mathrm{Cr}_{2} \mathrm{O}_{7}{ }^{2-}$ solution can also be converted with 20 min (Fig. S8(a)†), implying great potentials in practical realworld conditions. Variation of the concentration of $\mathrm{Cr}_{2} \mathrm{O}_{7}{ }^{2-}(40-$ $120 \mathrm{mg} \mathrm{L}^{-1}$ ) as a function of time shows that the photoreduction rate decreases along with the increased concentration (Fig. 6(b)), while there are not obvious change using ATD. It is the photocatalysis rather than photolysis plays a dominant role in $\mathrm{Cr}(\mathrm{vI})$ reduction. To simulate practical conditions, acid radicals $\left(\mathrm{NO}_{3}{ }^{-}, \mathrm{SO}_{4}{ }^{2-}\right.$ and $\left.\mathrm{H}_{2} \mathrm{PO}_{4}^{-}\right)$in $\mathrm{Cr}(\mathrm{vI})$ solution were also taken into account (Fig. 6(c)). Intriguingly, the existence of acid radicals makes a better removal efficiency of $\mathrm{Cr}(\mathrm{vI})$ in $10 \mathrm{~min}$. These acid radicals adsorbed on niobate surface act as electron donors and trap holes, thereby accelerating electron circulation. In principle, acid radicals play the same role to oxalic acid, thus improving photocatalytic efficiency. ${ }^{38}$ High resolution XPS scan of $\mathrm{Cr} 2 \mathrm{p}$ for niobate/diatomite was analyzed (Fig. 6(d) and S8(e, f) $\dagger$ ) to determine the oxidation state of $\mathrm{Cr}$ element after photoreduction. The $\mathrm{Cr} 2 \mathrm{p}$ peaks can be divided into three peaks at the binding energy of $576.8,581.8$ and $586.8 \mathrm{eV}$, which correspond to $\operatorname{Cr}(\mathrm{III}) 2 \mathrm{p}_{3 / 2}, \operatorname{Cr}(\mathrm{VI}) 2 \mathrm{p}_{3 / 2}$ and $\operatorname{Cr}(\mathrm{III}) 2 \mathrm{p}_{1 / 2}$, respectively, confirming $\mathrm{Cr}(\mathrm{VI})$ photoreduction of ending in less noxious Cr(III) species. ${ }^{12}$ ZNOD and SNOD samples also show well $\mathrm{Cr}(\mathrm{vI})$ photoreduction ability with the existence of oxalic acid (Fig. S8(b-d) $\dagger$ ) indicating that the obtained hybrid materials can provide convenient water-cleaning for the light-driven $\mathrm{Cr}(\mathrm{vI})$ elimination. It is also observed that there are not obvious change of microstructure and morphology of MNOD, ZNOD and SNOD after photocatalytic applications (Fig. S9 and S10†).

The oxidation state of $\mathrm{Fe}(\mathrm{III})$ is very stable in majority conditions and acts as an important role in oxygen uptake and metabolic processes. ${ }^{39}$ However, the removal of $\mathrm{Fe}(\mathrm{III})$ is 

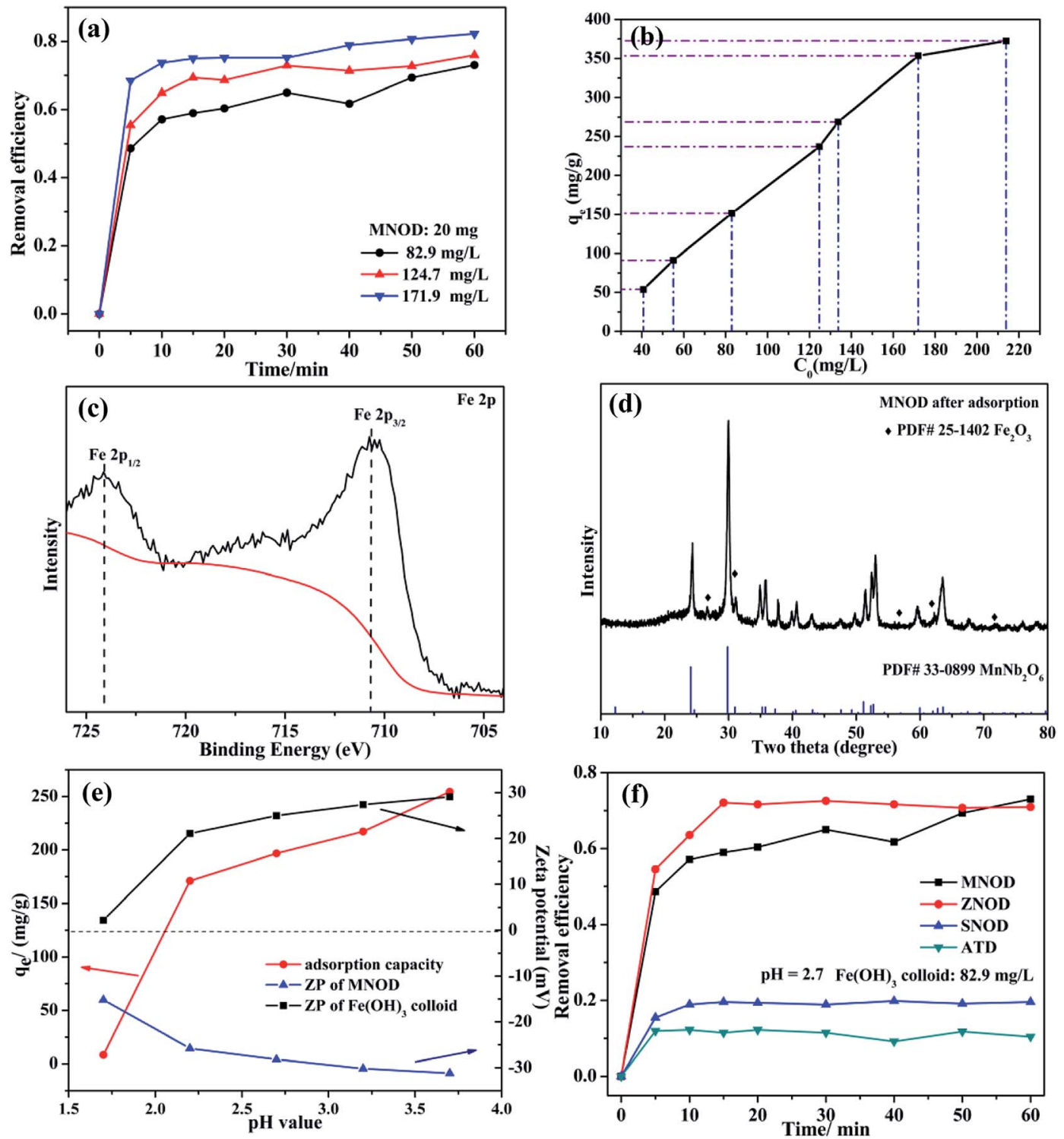

Fig. 7 (a) Adsorption efficiency and (b) adsorption capacity of Fe(OH) 3 colloids with different colloid concentration using MNOD (20 mg). (c) High resolution XPS scan of Fe $2 \mathrm{p}$ and (d) XRD pattern of MNOD after adsorption. (e) Effect of pH value on adsorption capacity and zeta potential of MNOD. (f) Comparison of removal efficiency of MNOD, ZNOD and SNOD (dosage: $20 \mathrm{mg}$ ) towards Fe(OH) 3 colloids.

essential, considering the overloading and deficiency of Fe(III) will trigger biological disorders in human body, like hepatic cirrhosis and anemia. ${ }^{40}$ Nonetheless, due to the strong hydrolytic tendency and a 6-fold coordination of $\mathrm{Fe}(\mathrm{III})$, aqueous ferric hydroxide species are the primary existence form in natural water. ${ }^{41}$ Thus the adsorption removal of ferric hydroxide $\left(\mathrm{Fe}(\mathrm{OH})_{3}\right)$ colloid in aqueous solution may be one of the most preferred routes for eliminating $\mathrm{Fe}(\mathrm{III})$ pollution. Fig. 7(a) shows the influence of adsorption time on the removal efficiency of $\mathrm{Fe}(\mathrm{OH})_{3}$ colloids by using MNOD at room temperature. The efficiency increases rapidly in the first $10 \mathrm{~min}$ and keeps steady subsequently. The adsorption capacity of MNOD shows a regular linear plot with the extension of $\mathrm{Fe}(\mathrm{OH})_{3}$ colloid concentration (Fig. 7(b)), which reaches saturated state when the concentration exceeds $171.9 \mathrm{mg} \mathrm{L}^{-1}$. High resolution XPS scan of $\mathrm{Fe} 2 \mathrm{p}$ is analyzed to gain insights into $\mathrm{Fe}(\mathrm{OH})_{3}$ colloid adsorption (Fig. 7 (c)). There are two typical peaks Fe $2 \mathrm{p}_{3 / 2}$ and Fe $2 \mathrm{p}_{1 / 2}$ located at $711.4 \mathrm{eV}$ and $724.5 \mathrm{eV}$, indicating the oxidation state of Fe element is $\mathrm{Fe}(\mathrm{III}){ }^{42}$ Noteworthy that the transformation of $\mathrm{Fe}(\mathrm{OH})_{3}$ into $\mathrm{Fe}_{2} \mathrm{O}_{3}$ is considered as a topotatic reaction in practical condition. ${ }^{43}$ The XRD pattern suggests that $\mathrm{Fe}_{2} \mathrm{O}_{3}$ exists on MNOD surface after adsorption, which is consistent with the XPS results (Fig. 7(d)). The red color of MNOD after adsorption also demonstrates the formation of $\mathrm{Fe}_{2} \mathrm{O}_{3}$ particles (Fig. S11†). Zeta potential was employed to analyze the surface potential of $\mathrm{Fe}(\mathrm{OH})_{3}$ colloids and MNOD adsorbent in different $\mathrm{pH}$ values (Fig. $7(\mathrm{e})$ ). The $\mathrm{Fe}(\mathrm{OH})_{3}$ colloids are positive while the surface of MNOD is full of negative charges. The driving force of this adsorption process is thus electrostatic attraction. The variation of adsorption capacity at a range $\mathrm{pH} 3.7$ to 1.7 results from the potential difference between MNOD and $\mathrm{Fe}(\mathrm{OH})_{3}$ colloid. While in highly 



Fig. 8 (a) Adsorption efficiency of $\mathrm{Pb}($ II) ions using MNOD (20 mg). (b) Effect of solution $\mathrm{pH}$ on the adsorption capacity. (c) XRD pattern, (d) high resolution XPS scan of $\mathrm{Pb} 4 \mathrm{f}$ after adsorption, and (e) $\mathrm{C}$ 1s of MNOD before and after adsorption. (f) Comparison of removal efficiency of MNOD, ZNOD, and SNOD (dosage: $20 \mathrm{mg}$ ) towards $\mathrm{Pb}(\mathrm{II})$ ions.

acidic environment $(\mathrm{pH}=1.7)$, the adsorption capacity has a sudden fall, which is attributed to the structure destruction of $\mathrm{Fe}(\mathrm{OH})_{3}$ colloids in strong acid solution. Compared with MNOD, the removal capacity of ZNOD is comparatively alike especially in the solution $\mathrm{pH}=2.7$, and it is smaller for SNOD sample (Fig. 6(f) and S12 $†$ ). Zeta potential analysis indicates that the surface potentials of ZNOD and SNOD are -29.2 and $26.3 \mathrm{mV}$ in aqueous solution ( $\mathrm{pH}=2.7$ ), respectively (Fig. S13 $\dagger$ ). The electrostatic attraction identically dominates the adsorption process of $\mathrm{Fe}(\mathrm{OH})_{3}$ colloids with ZNOD and SNOD.

As a highly bio-incompatible toxic ion, $\mathrm{Pb}$ (II) is characterized by its non-biodegradability and carcinogenicity. ${ }^{44}$ The physical adsorption route shall be of its high efficiency, cost- effectiveness as well as easy operation for eliminating $\mathrm{Pb}(\mathrm{II})$ contamination. ${ }^{45}$ However, considering the safe concentration for $\mathrm{Pb}$ (II) in water discharge is as low as $1.0 \mathrm{mg} \mathrm{L}^{-1}$ in China, ${ }^{46}$ chemisorption may be one of the most suitable ways for deep elimination of $\mathrm{Pb}(\mathrm{II})$ ions to avoid the production of lots of mixed slurry and the use of high-energy separation processes such as ultrafiltration or nanofiltration. The adsorption tests in Fig. 8 show that the removal efficiency of $\mathrm{Pb}$ (II) increases rapidly and reaches saturation stability within 15 min by using MNOD sample at room temperature (Fig. 8(a)). Considering practical severe application conditions and avoiding precipitation of lead hydroxides, the influence of $\mathrm{pH}(2.5-5.5)$ is also taken into account. As depicted in Fig. 8(b), the adsorption capacity shows 
a gradual decrease with more acid environment which influences the surface potential. XRD patterns and high resolution XPS scan of MNOD sample after $\mathrm{Pb}$ (II) adsorption indicate that, intriguingly, chemisorption dominates the process and there are $\mathrm{PbC}_{2} \mathrm{O}_{4}$ and $\mathrm{PbO}_{2}$ (Fig. 8(c)) formed on the material surface. The high resolution XPS scan of $\mathrm{Pb} 4 \mathrm{f}$ (Fig. 8(d)) reveals that there are two peaks of $\mathrm{Pb}$ (II) $(138.4 \mathrm{eV}$ and $143.5 \mathrm{eV}$ ) and $\mathrm{Pb}$ (IV) $(136.4 \mathrm{eV}$ and $141.2 \mathrm{eV}) .{ }^{47,48}$ In our preparation process, $\left(\mathrm{NH}_{4}\right)_{2} \mathrm{C}_{2} \mathrm{O}_{4}$ was used as a regular chemical agent for inducing niobate crystal heteronucleation by surface complex and hybrid. Two typical peaks of $\mathrm{C}$ 1s located at $288.1 \mathrm{eV}$ and $288.9 \mathrm{eV}$ correspond to $\mathrm{C}=\mathrm{O}$ and $\mathrm{O}=\mathrm{C}-\mathrm{OH}$ (Fig. 8(e)), demonstrating the surface complexation of $\mathrm{C}_{2} \mathrm{O}_{4}{ }^{2-}$. Noteworthy that even though going through adsorption process, as depicted in XPS data, these oxygen-containing $\mathrm{C}_{2} \mathrm{O}_{4}{ }^{2-}$ groups exist on MNOD surface, thus facilitating crystal nucleation of $\mathrm{PbC}_{2} \mathrm{O}_{4}$ during $\mathrm{Pb}$ (II) adsorption. It is reasonable to assume that the variation of removal efficiency in different $\mathrm{pH}$ value is associated with surface state modified by oxalate species. As illustrated in eqn (3) and (4), a competition between $\mathrm{H}^{+}$and $\mathrm{Pb}$ (II) combining with $\mathrm{C}_{2} \mathrm{O}_{4}{ }^{2-}$ occurs simultaneously. In a more acid environment $(\mathrm{pH}$ $=2.5-5.5), \mathrm{H}^{+}$ions occupy the most part of binding sites and hinder $\mathrm{Pb}(\mathrm{II})$ adsorption process. Moreover, according to XPS result in Fig. $3\left(\mathrm{c}_{1}\right), \mathrm{Mn}(\mathrm{III})$ exists in $\mathrm{MnNb}_{2} \mathrm{O}_{6}$. The standard electrode potential of $\mathrm{Mn}$ (III) $(1.51 \mathrm{~V})$ is higher than $\mathrm{PbO}_{2}(1.46$ $\mathrm{V})$, as illustrated in eqn (5) and (6), and part of $\mathrm{Pb}$ (II) ions contacted with $\mathrm{MnNb}_{2} \mathrm{O}_{6}$ surface can be oxidized into $\mathrm{Pb}(\mathrm{Iv})-\mathrm{PbO}_{2}$.

$$
\begin{gathered}
\mathrm{C}_{2} \mathrm{O}_{4}{ }^{2-}+\mathrm{H}^{+} \rightarrow \mathrm{HC}_{2} \mathrm{O}_{4}{ }^{-} \\
\mathrm{C}_{2} \mathrm{O}_{4}{ }^{2-}+\mathrm{Pb}^{2+} \rightarrow \mathrm{PbC}_{2} \mathrm{O}_{4} \\
\mathrm{Mn}^{3+} \rightarrow \mathrm{Mn}^{2+}+\mathrm{e}^{-} \varphi=1.51 \mathrm{~V} \\
\mathrm{PbO}_{2}+4 \mathrm{H}^{+}+2 \mathrm{e}^{-} \leftrightharpoons \mathrm{Pb}^{2+}+2 \mathrm{H}_{2} \mathrm{O} \varphi=1.46 \mathrm{~V}
\end{gathered}
$$

ZNOD possesses similar adsorption behavior towards $\mathrm{Pb}$ (II) ions by forming $\mathrm{PbC}_{2} \mathrm{O}_{4}$ (Fig. 8(f) and $\mathrm{S} 14 \dagger$ ). However, the adsorption capacity of SNOD is relatively low on account of a weak modification by oxalate species (Fig. S15 $\dagger$ ). For practical usage, the structure-sensitive chemisorption of MNOD and ZNOD is more suitable for deep removal of $\mathrm{Pb}$ (II) ions compared with physical absorption, and one option we are working on is to produce MNOD and ZNOD with more abundant surface carboxyl groups.

We have further studied the stability and reusability of MNOD by collecting and reusing for four cycles. As shown in Fig. S16. $\dagger$ The collected MNOD powder was directly reused for $\mathrm{Cr}(\mathrm{vI})$ photoreduction, and was renewed via dispersing the powder in $0.1 \mathrm{M} \mathrm{HNO}_{3}$ for $3 \mathrm{~h}$ after $\mathrm{Fe}(\mathrm{OH})_{3}$ colloid adsorption or $\mathrm{Pb}(\mathrm{II})$ ion adsorption. Experimental results showed that the renewed MNOD materials keep almost the same $\mathrm{Fe}(\mathrm{OH})_{3}$ adsorption performance, while the reusability of MNOD for $\mathrm{Cr}(\mathrm{VI})$ photoreduction and $\mathrm{Pb}$ (II) elimination demonstrated great decrease due to existing surface chemical reactions in their photoreduction and chemisorption processes.

\section{Conclusions}

In summary, we developed a general, scalable and controllable strategy to in situ grow nanostructured niobates on alkali treated diatomite with the assistance of $\left(\mathrm{NH}_{4}\right)_{2} \mathrm{C}_{2} \mathrm{O}_{4}$ regardless of their composition and structure. The central synthesis is based on simultaneous surface etching activation of diatomite by $\mathrm{NH}_{3} \cdot \mathrm{H}_{2} \mathrm{O}$ during complexation dissolution of $\mathrm{Nb}_{2} \mathrm{O}_{5}$ with $\mathrm{H}_{2} \mathrm{C}_{2} \mathrm{O}_{4}$, allowing the heterogeneous crystallization process to proceed with controllable growth kinetics. Calculation results via $\mathrm{PBE}$ exchange-correlation (XC) function of GGA demonstrate that the adsorption of $\mathrm{Nb}$ atom owns a lowest $E_{\text {ad }}$ compared with other three atoms of $\mathrm{Mn}, \mathrm{Zn}$, and $\mathrm{Sn}$, meaning that $\mathrm{Nb}$ atoms will band together with $\mathrm{O}$ atoms more preferentially on the $\mathrm{SiO}_{2}$ surface and take the lead in heterogeneous nucleating process of Nb-O-Mn (or $\mathrm{Zn}, \mathrm{Sn}$ ) networks. The possibility of combining the advantages of natural mineral diatomite and nanostructured materials provides the access to versatile functionalities of water purification. The obtained composites possess well removal ability for $\mathrm{Cr}(\mathrm{VI}), \mathrm{Fe}(\mathrm{III})$ and $\mathrm{Pb}$ (II) ions owing to their great dispersity and high surface area. Typically, MNOD exhibits well photoreduction ability for $\mathrm{Cr}(\mathrm{vI})$ both under xenon lamp and sunlight irradiation, and adsorption capacity for $\mathrm{Fe}(\mathrm{OH})_{3}$ colloids and $\mathrm{Pb}$ (II) ions. The electrostatic attraction dominates the adsorption process of $\mathrm{Fe}(\mathrm{OH})_{3}$ colloids, and surface chemistry-related chemisorption is involved in the deep purification of $\mathrm{Pb}$ (II) polluted water. Given the low-cost and ecofriendly nature of the obtained diatomite-based materials, this work really offers a realistic methodology for diatomite utilization in water-cleaning field.

\section{Conflicts of interest}

The authors declare that they have no conflict of interest.

\section{Acknowledgements}

This study was funded by National Key R\&D Program of China (2017YFB0310804), National Natural Science Foundation of China (No. 51621003) and Beijing municipal high level innovative team building program (No. IDHT 20170502).

\section{References}

1 D. Blowes, Science, 2002, 295, 2024-2025.

2 C. Göde, M. L. Yola, A. Yılmaz, N. Atar and S. Wang, J. Colloid Interface Sci., 2017, 508, 525-531.

3 J. Ma, J. Luo, Y. Liu, Y. Wei, T. Cai, X. Yu, H. Liu, C. Liu and J. C. Crittenden, J. Mater. Chem. A, 2018, 6, 20110-20120.

4 S. Rezania, S. M. Taib, M. F. Md Din, F. A. Dahalan and H. Kamyab, J. Hazard. Mater., 2016, 318, 587-599.

5 N. S. Kovalevskiy, M. N. Lyulyukin, D. S. Selishchev and D. V. Kozlov, J. Hazard. Mater., 2018, 358, 302-309.

$6 \mathrm{X}$. Hu, L. Deng, H. Ouyang and H. Wang, RSC Adv., 2018, 8, 28032-28040.

7 B. Wang, F. C. de Godoi, Z. Sun, Q. Zeng, S. Zheng and R. L. Frost, J. Colloid Interface Sci., 2015, 438, 204-211. 
8 X. Liu, X. Xu, J. Sun, A. Alsaedi, T. Hayat, J. Li and X. Wang, Chem. Eng. J., 2018, 343, 217-224.

9 J. F. Mukerabigwi, S. Lei, L. Fan, H. Wang, S. Luo, X. Ma, J. Qin, X. Huang and Y. Cao, RSC Adv., 2016, 6, 31607-31618.

10 J. Li, J. Xu, Z. Xie, X. Gao, J. Zhou, Y. Xiong, C. Chen, J. Zhang and Z. Liu, Adv. Mater., 2018, 30, 1800548.

11 N. Ezzatahmadi, T. Bao, H. Liu, G. J. Millar, G. A. Ayoko, J. Zhu, R. Zhu, X. Liang, H. Hee and Y. Xi, RSC Adv., 2018, 8, 7687-7696.

12 J. Wu, J. Wang, H. Li, Y. Li, Y. Du, Y. Yang and X. Jia, Appl. Surf. Sci., 2017, 403, 314-325.

13 Y. Jin, D. Jiang, D. Li and M. Chen, Catal. Sci. Technol., 2017, 7, 2308-2317.

14 F. Huang, Q. Zhou, L. Li, X. Huang, D. Xu, F. Li and T. Cui, J. Phys. Chem. C, 2014, 118, 19280-19286.

15 A. Orera, F. Garcia-Alvarado and J. T. S. Irvine, Chem. Mater., 2007, 19, 2310-2315.

16 L. P. Cruz, J.-M. Savariault, J. Rocha, J.-C. Jumas and J. D. Pedrosa de Jesus, J. Solid State Chem., 2001, 156, 349354.

17 J. Wu, J. Wang, H. Li, Y. Du, X. Jia and B. Liu, CrystEngComm, 2014, 16, 9675-9684.

18 L. Wan, H. Song, J. Ma, Y. Ren, X. Cheng, J. Su, Q. Yue and Y. Deng, ACS Appl. Mater. Interfaces, 2018, 10, 13028-13039.

19 G. Kresse and J. Furthmüller, J. Phys.: Condens. Matter, 1996, 54, 11169-11186.

20 J. Chou, C. Hsing, C. Wei, C. Chen and C. Chang, J. Phys.: Condens. Matter, 2013, 25, 125305.

21 J. Chou, C. Hsing, J. Chen, J. Lee and C. Wei, Surf. Sci., 2013, 616, 137-142.

22 E. J. G. Santos, A. Ayuela and D. Sánchez-Portal, J. Phys. Chem. C, 2012, 116, 1174-1178.

23 D. K. Mishra, S. K. Samad, A. K. Varma and V. A. Mendle, J. Nat. Gas Sci. Eng., 2018, 52, 25-43.

24 F. Tang, D. Su, Y. Tang and G. Fang, Sol. Energy Mater. Sol. Cells, 2015, 141, 218-224.

25 S. Ida, A. K. Thapa, Y. Hidaka, Y. Okamoto, M. Matsuka, H. Hagiwara and T. Ishihara, J. Power Sources, 2012, 203, 159-164.

26 Y. Tong and Y. Wang, Mater. Charact., 2009, 60, 1382-1386.

27 A. Bhattacharjee and M. Ahmaruzzaman, Mater. Lett., 2015, 157, 260-264.

28 C. Nethravathi and M. Rajamathi, Carbon, 2008, 46, 19941998.
29 B. Wang, F. C. de Godoi, Z. Sun, Z. Sun, Q. Zeng, S. Zheng and R. L. Forst, J. Colloid Interface Sci., 2015, 438, 204-211.

30 Y. Xu, L. Zhang, M. Yin, D. Xie, J. Chen, J. Yin, Y. Fu, P. Zhao, H. Zhong, Y. Zhao and X. Wang, Appl. Surf. Sci., 2018, 440, 170-176.

31 M. Fukushima, E. Yasuda, Y. Nakamura, M. Shimizu, Y. Teranishi and L. M. Manocha, J. Sol-Gel Sci. Technol., 2005, 34, 15-21.

32 G. Lakshminarayana, S. O. Baki, A. Lira, M. I. Sayyed, I. V. Kityk, M. K. Halimah and M. A. Mahdi, J. Mater. Sci., 2017, 52, 7394-7414.

33 Q. Li, T. Kako and J. Ye, Int. J. Hydrogen Energy, 2011, 36, 4716-4723.

34 T. Qian, J. Li and Y. Deng, Sci. Rep., 2016, 6, 32392.

35 D. S. Conceição, C. A. L. Graça, D. P. Ferreira, A. M. Ferraria, I. M. Fonseca, A. M. Botelho do Rego, A. C. S. C. Teixeira and L. F. Vieira Ferreir, Microporous Mesoporous Mater., 2017, 253, 203-214.

36 D. Zhang, Z. Qin, X. Yang, H. Zhu and M. Cao, J. Sol-Gel Sci. Technol., 2011, 57, 31-35.

37 R. M. Tripathi, R. Pragadeeshwara Rao and T. Tsuzuki, RSC Adv., 2018, 8, 36345-36352.

38 T. Peng, C. Hu, X. Hu, X. Zhou and J. Qu, Catal. Lett., 2012, 142, 646-654.

39 L. L. Dunn, Y. S. Rahmanto and D. R. Richardson, Trends Cell Biol., 2007, 17, 93-100.

40 S. J. Dixon and B. R. Stockwell, Nat. Chem. Biol., 2014, 10, 917.

41 F. Huang, Q. Zhou, L. Li, X. Huang, D. Xu, F. Li and T. Cui, J. Phys. Chem. C, 2014, 118, 19280-19286.

42 J. Li, J. Xu, W. Dai, H. Li and K. Fan, Appl. Catal., B, 2009, 85, 162-170.

43 A. Stefansson, Environ. Sci. Technol., 2007, 41, 6117-6123.

44 H. Zhang, A. Wu, H. Fu, L. Zhang, H. Liu, S. Zheng, H. Wan and Z. Xu, RSC Adv., 2017, 7, 41228-41240.

45 L. Kong, Z. Li, X. Huang, X. Huang, S. Huang, H. Sun, M. Liu and L. Li, J. Mater. Chem. A, 2017, 5, 19333-19342.

46 L. Zhang, X. Lin, J. Wang, F. Jiang, L. Wei, G. Chen and X. Hao, Sci. Rep., 2016, 6, 30455.

47 S. He, Y. Li, L. Weng, J. Wang, J. He, Y. Liu, K. Zhang, Q. Wu, Y. Zhang and Z. Zhang, Sci. Total Environ., 2018, 637-638, 69-78.

48 C. Park, Y. Son and M. Won, Microchem. J., 2005, 80, 201206. 